different distribution pattern. The true specificity for pyridoxal-phosphatase should be biochemically investigated in the future. (The detailed report will be published in the Kumamoto Igakkai Zasshi, Vol. 37, 1963).

\title{
Discussion
}

Dr. Okawa: Do you mean the existence of a specific enzyme "pyridoxal phosphatase" ? I think further studies are necessary to assert its specificity.

Dr. Shiraishi : I agree with you. The specificity of "pyridoxal phosphatase is not concluded from the present studies and it should be investigated by the further studies such as the action of inbibitors and activators including $\mathrm{NaF}$.

\section{On the Acid Phosphatase Activity of Kupffer Cells}

\author{
Nobuhiko TaKahashi and Itaru Watanabe \\ From the pathological laboratory of Prof. K. Akazaki, Tohoku \\ University School of Medicine, Sendai, Japan
}

This investigation was performed to observe the functions of reticuloendothelial cells (RE cells) by means of enzymohistochemical method. It has been well reported by many workers that RE cells were rich in acid phosphatase (ac-ph.) activity ${ }^{1,2,3,4)}$. The enzyme, moreover, has been considered to have some relation to pinocytosis and phagocytosis of $R E$ cells $^{5,6,7,8)}$. From these points of view, we made an observation how the ac-ph. activity of the Kupffer cells would be changed when they were activated or inhibited on phagocytic activity. To determine the phagocytic activity of the Kupffer cells the carbon black clearance test was applied.

At the same time the ac-ph. activities of subcutaneous histiocytes were observed.

Procedures: All the experiments were carried out with male rabbits weighing 2.0 to $2.5 \mathrm{~kg}$. For the activation of phagocytic activity of RE cells, $5 \mathrm{cc} / \mathrm{kg}$ of typhoid vaccine (T.V.) was once injected into the peritoneal cavity, and for the inhibition, $7.5 \mathrm{mg} / \mathrm{kg}$ of prednisolone (Pr.) into the femoral muscle. Liver pieces and subcutaneous connective tissue were biopsied 4 days after these procedures. The former was immediately immersed into fixative for 18 hours and the latter was soon stretched on object glasses and dried without further fixation ${ }^{9}$. The fixative for the liver pieces was the cold $10 \%$ formalin, adjusted to $\mathrm{pH} 7.2$ by $0.33 \mathrm{M}$ veronal buffer and added $5 \%$ sucrose after Holt ${ }^{10)}$. From these pieces ordinary frozen sections $(10 \mu)$ were made.

The substrate medium was prepared after Gomori ${ }^{11)}$; $50 \mathrm{ml}$. of $3.0 \mathrm{Na}-$ glycerophosphate, $0.6 \mathrm{gm}$ lead nitrate and $500 \mathrm{ml}$. of $0.05 \mathrm{M}$ acetate buffer with 
$\mathrm{pH}$ 4.6. Incubation time, at $37^{\circ} \mathrm{C}$, was 2 hours for the liver sections and 7 hours for the subcutaneous connective tissue ${ }^{3,5}$.

On the other groups of the similarly treated rabbits, carbon black clearance was measured after the method of Halpern et $\mathrm{al}^{122}$.

Results: Phagocytic index K., determined by the carbon black clearance, showed a heightened value in the T.V.-treated group and a lowered one in the Pr.-treated group as shown in Fig. A.

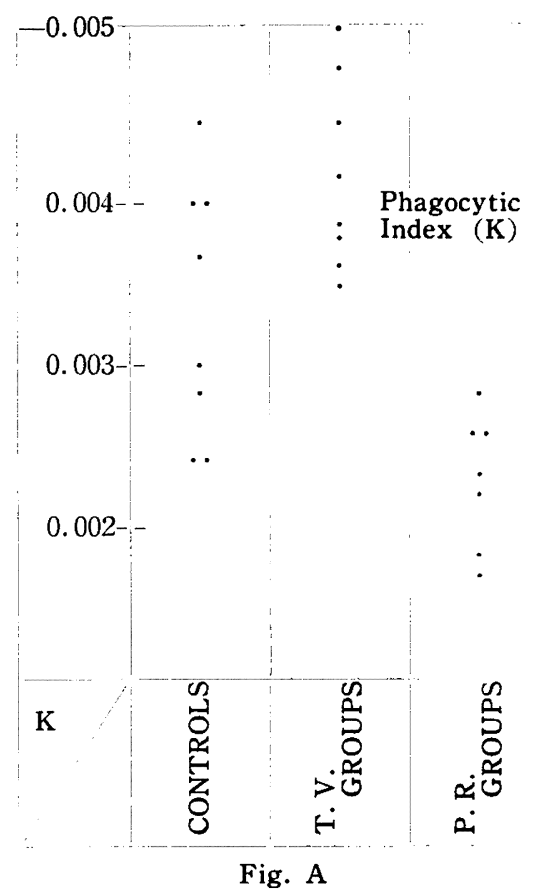

The ac-ph. activity of the untreated liver was manifested by the intense ac-ph. activity of Kupffer cells. Moderate ac-ph. activity was also seen in the interstitial cells and the epithelial cells of the bile ducts of the Glisson's sheath, but liver cells showed only a trace of enzymatic activity along the bile canaliculi at the peripheral zones of the liver lobules. The Kupffer cells with the ac-ph. activity were seen more frequently in the peripheral zones.

The ac-ph. activity was diffusely recognized as fine granules which were intermingled with rather coarse ones in the cytoplasms and, sometimes, around the nuclei of the Kupffer cells. The fine granules were diffusely distributed in their cytoplasms, while the coarse ones were found at the edge of their nuclei or, sometimes, taking polymorphous patterns, at the periphery of their cytoplasms. In the T.V. cases the Kupffer cells increased in number and became larger in size and often tended to free themselves from the endothelial lining. The ac-ph. activity of these cells increased to the grade that they could be seen in the central zones of the liver lobules. The ac-ph. active granules in these Kupffer cells were seen increased in number and became coarser. By Pr.-treatment, the Kupffer cells decreased in number and became 
flat in figure. The ac-ph. activity of these cells was markedly decreased and was only seen near the Glisson's sheath.

The ac-ph. activity of the subcutaneous connective tissue revealed similar qualitative tendency as that of the Kupffer cells under these procedures. By T. V.-treatment, histiocytes inclined to increase in number and to group themselves togather. The ac-ph. active granules of these cells were markedly increased in number and varied in size. As observed in the Kupffer cells, a large and round granule was sometimes found near the nucleic concavity. Though, by Pr.-treatment, the decrease in cell number of the subcutaneous connective tissue was not distinct, the enzyme activity of the histiocytes was decreased significantly.

Comment: The carbon black clearance has been known to present mainly the phagocytic activity of the Kupffer cells. In our experiments, it was hightened by the T.V. and lowered by the Pr.-treatment, and the ac-ph. activity of the Kupffer cells was also increased by the T.V.-treatment and decreased by the Pr.-treatment. For this reason, the ac-ph. activity of the Kupffer cells may be applicable for the estimation of their phagocytic functions.

The subcutaneous histiocytes, on the other hand, showed the same changes of ac-ph. activity as that of the Kupffer cells. So, it might be expected that the change of phagocytic function of the subcutaneous histiocytes was similar to that of the Kupffer cells. The activating effects of T.V. on the RE cells were well established by many workers ${ }^{2,6,13)}$, but the effects of Pr. on these cells have not yet been clearly understood ${ }^{6}$. We found that $7.5 \mathrm{mg} / \mathrm{kg}$ of $\mathrm{Pr}$. inhibited the phagocytic activity of the RE cells 4 days after injection, but when 2.5 and $5 \mathrm{mg} / \mathrm{kg}$ of $\operatorname{Pr}$. were injected for 3 and 5 days, respectively, the evidences of elevated phagocytic functions of the RE cells was only occasionally observed. For clarifying the action of corticosteroid hormones on the functions of RE cells, further studies must be made.

Most parts of these fine granules, which were found diffusely in the RE cells, were suspected to be identical to lysosmes ${ }^{7,8)}$. As Hosoda has noted, the ac-ph. activity of the subcutaneous histiocytes in the activated condition was recognized as large coarse granules at the site regarded as the Golgi area and, at times, realized as phagocytosing vacuoles ${ }^{5}$. Similar patterns were also observed in the Kupffer cells.

In our observation, ac-ph. of the Kupffer cells and subcutaneous histiocytes had optimal $\mathrm{pH}$ at 4.6 and they could be slightly inhibited by $0.4 \% \mathrm{HCHO}$, and completely by $0.01 \mathrm{M}$ sodium fluoride and $0.01 \mathrm{M} \mathrm{L}$-tartrate, and furthermore, as the ac-ph. in the bile and erythrocytes was not inhibited by L-tartrate, it seemed that the ac-ph. in the Kupffer cells might be of neither biliary nor erythrocytic origin, but might belong to the phosphomonoesterase II after Folly and Kay ${ }^{14,15,16,17)}$. However, it remains unsettled whether the histochemical ac-ph. of the liver cells, of the Kupffer cells or of the other cells as the prostatic are of different kinds or not. Serum ac-ph. did not show significant changes under the T.V. or Pr.-treatment. These findings seemed to suggest that the ac-ph. of RE cells was not phagocytosed one. 


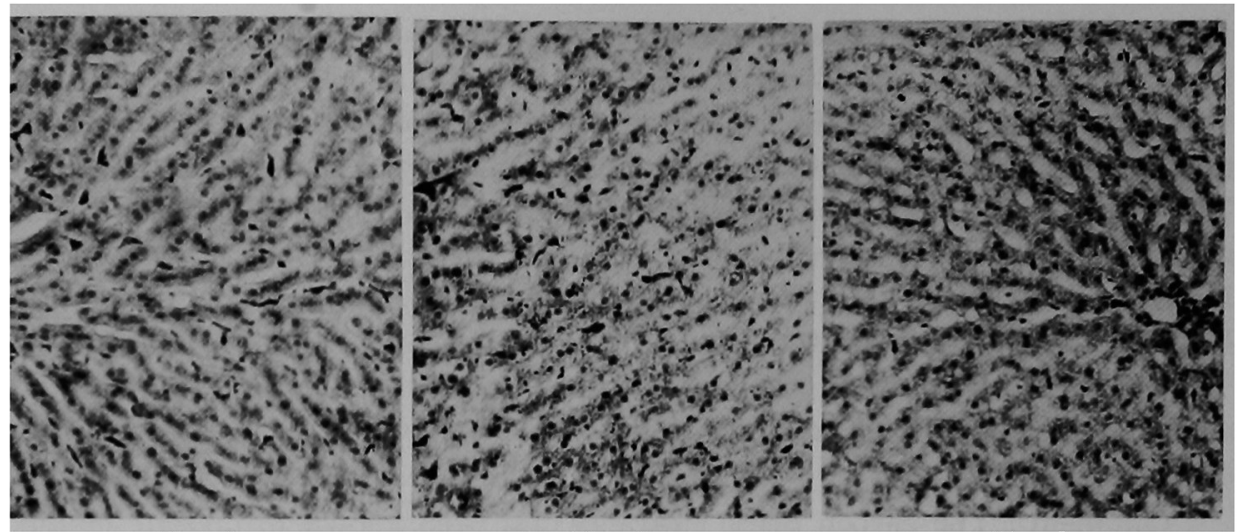

$$
\text { Fig. } 1 .
$$

Fig. 2.

Fig. 3.

The Kupffer cells in liver lobules.

T. V. treament.

Control.

Pr.-treament.

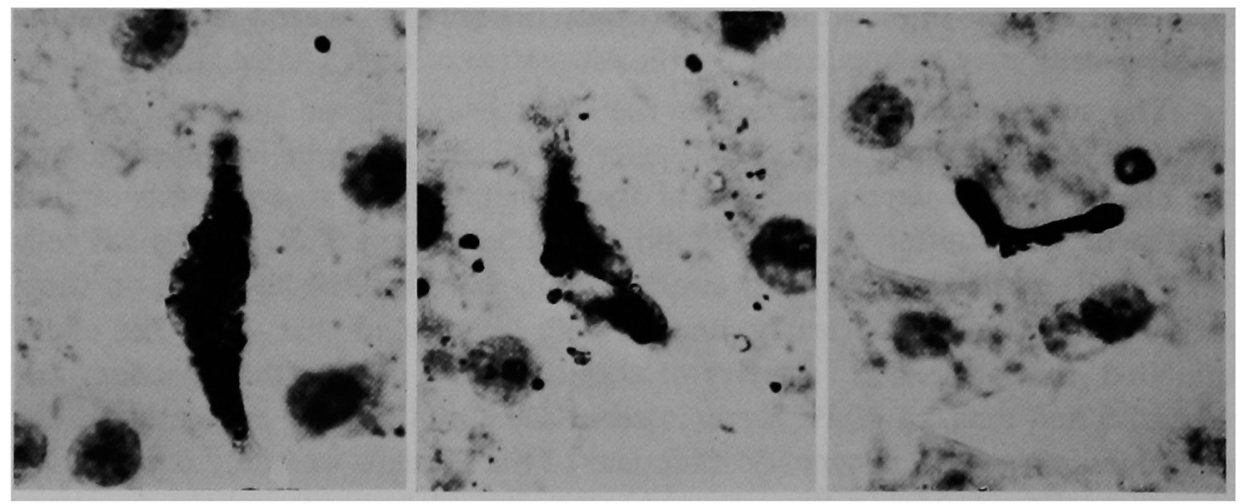

Fig. 4.

Fig. 5.

Fig. 6.

The Kupffer cell.

T. V. treament.

Control.

Pr.-treament.

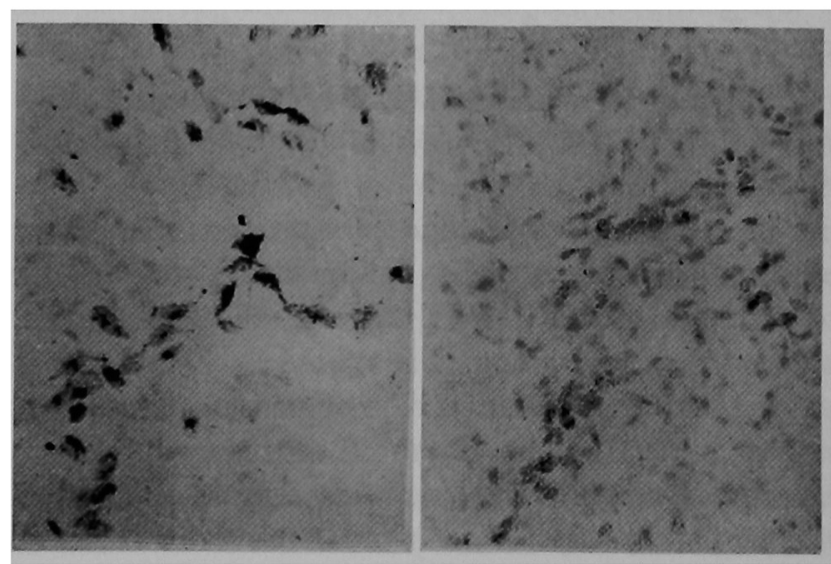

Fig. 7.

Fig. 8.

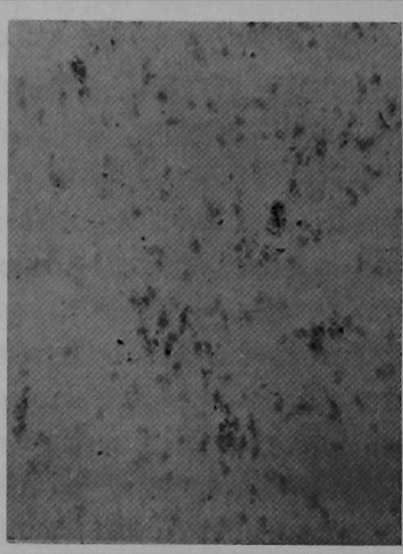

Fig. 9.

The subcutaneous histiocytes.

T. V. treament.

Control.

Pr.-treament. 
Summary: 1. An investigation was performed on the RE cells of rabbits by way of enzymohistochemistry and carbon black clearance. 2. By the typhoid vaccine treatment the acid phosphatase activity of Kupffer cells increased and carbon black clearance heightened, while by the prednisolone trearment they went vice versa. 3. Remarkable parallelism was found between the Kupffer cells and the subcutaneous histiocytes on their acid phosphatase activity and morphological behaviours under the typhoid vaccine or prednisolone treatment. 4. Some considerations were made on the nature of acid phosphatase in the RE cells.

\section{References}

1) Gedigk, P. u. Bontke, E. Virchows Arch., 330, 538, $1957 . \quad 2$ 2) Barka, T. J. Histochem. Cytochem., 8, 320, 1960, 10, 231, $1962 . \quad$ 3) Hosoda, S. \& Takase, S. Proc. Jap. Histochem. Assoc., 1, 174, $1960 . \quad$ 4) Novikoff, A. B. \& Essner, E. Am. J. Med., 20, 102, 1960. 5) Hosoda, Tr. Soc. Path. Jap., 50, (1) 23, $1961 . \quad$ 6) Thorbeck, G. J. \& Old, L. J. J. Histochem. Cytochem., 9, 325, $1961 . \quad 7)$ de Duve, C. Nature, 187, 836, $1960 . \quad$ 8) Essner, E. \& Novikoff, A. B. J. Bioph. Biochem. Cty., 9, 773, 1961. 9 9) Hosoda, S. \& Nakamura, K. J. Histochem. Cytochem. 8, 72, 1960.110$)$ Holt, S. J. \& Hicks, R. M. J. Bioph. Biochem. Cyt. 11, 31, $1961 . \quad 11)$ Gomori, G. Microscopic Histochemistry, Chicago, 1952.112$)$ Halpern et al. Physiopathology of R.E.S., A symposium, Oxford, 1958 13) Kojiuma, M. R.E.S. Bull., 3, 3, $1957 . \quad$ 14) Folly, S. J. \& Kay, H. D. Ergeb. Enzymforsch., Band V, 159, 1936. 15) Abul Fadl, M.A.M. \& King, E. J. Biochem. J., 45, 51, 1949.1 16) Goodlad, G.A.J. \& Mills, G. T. Biochem. J., 66, 346, $1957 . \quad 17)$ Walker, B. S. et al. Am. J. Cl. Path., 24 (2), 807, 1954.

\section{Discussion}

Dr. Mizutani :

The studies on acid-p-ase activity in the Kupfer cells have been reported in the recent J. Histochem \& Cytochem. ( ).

In my experiment, the cold formol fixation resulted in the diminution of acid-p-ase activity in the hepatic cells remaining the activity in the Kupfer cells, otherwise the both cells showed the marked activity.

In your present studies, the incubation time seems to be too long, and so, it caused a "diffusion".

Dr. Takahashi :

We have already studied the influence of fixatives and incubation times for the detection of acid-p-ase activity in the Kupffer cells, and concluded that the present conditions gave the best results.

The previous studies in the subcutaneous tissues also showed the adequate incubation time. The incubation period of time should be shorter when the activity is strong in the case of inflammation.

Dr. Ogawa :

In your present studies, lysosomes in the Kupffer cells seem to be preserved with their enzyme activites, but, the acid-p-ase reaction in the hepatic cells are diffuse suggesting its release from lysosomes. I would like to know the conditions of the fixation and incubation in the present studies.

Dr. Takahashi :

The formol calcium solution adjusted to $\mathrm{pH} .7 .2$ with $\mathrm{NaOH}$ also gave the good results but it somewhat diminished the enzyme activity. Therefore, the formol solution adjusted with veronal buffering solution is preferable. 